\title{
Model-informed precision dosing of levetiracetam in pediatrics population
}

\author{
Julia Macente $^{1}$, Frederico Martins ${ }^{2}$, Rodolfo Bonan ${ }^{1}$, Edilainy Caleffi-Marchesini ${ }^{1}$, \\ Leonardo Pereira ${ }^{3}$, Priscila Lima ${ }^{4}$, Elza Kimura ${ }^{5}$, and Andrea Diniz ${ }^{6}$ \\ ${ }^{1}$ State University of Maringá \\ ${ }^{2}$ University of Sao Paulo Faculty of Pharmaceutical Sciences of Ribeirao Preto \\ ${ }^{3}$ University of Sao Paulo \\ ${ }^{4}$ Barão de Mauá University Centre \\ ${ }^{5}$ Universidade Estadual de Maringá \\ ${ }^{6}$ Universidade Estadual de Maringa Centro de Ciencias da Saude
}

April 17, 2021

\begin{abstract}
Aims: Assessing the suitability and safety of doses of levetiracetam in pediatrics using physiologic-based pharmacokinetic (PBPK) modeling. Methods: A PBPK model of levetiracetam was developed and validated for healthy adults and scaled for children (0.5 to 12 years old). Prediction of levetiracetam exposure at steady- state, were carried out for different therapeutic regimens to achieve the target of Cmax values within the therapeutic range of 5 to $46 \mu \mathrm{g} \mathrm{ml}-1$. Then, a multivariate linear regression analysis (MLR) was applied to correlate the simulated data with covariates: dose, therapeutic regimen, sex, age and body weight $(\mathrm{BW})$, to describe the best model prediction for the initial dosing in pediatrics. Results: The results indicated the suitability of the PBPK model for adults and pediatrics. For children aged 0.5 to 6 y.o. the dose range capable of reaching the pharmacokinetic target is between 10 and $100 \mathrm{mg} \mathrm{kg-1}$ day-1, for 7 to 9 y.o. doses between 20 and $90 \mathrm{mg} \mathrm{kg}-1 \mathrm{day}-1$, and for 10 to 12 y.o. doses between 20 to $80 \mathrm{mg} \mathrm{kg-1}$ day-1. Further, the MLR related Cmax to dose, therapeutic regimen, and BW. Conclusions: For 3 daily administrations, it is suggested that maximum daily doses of $80 \mathrm{mg}$ kg- 1 could be used for ages between 0.5 and 6 y.o. and $100 \mathrm{mg} \mathrm{kg-1}$ for ages above 7 years old, since they weigh below $50 \mathrm{~kg}$. The PBPK model lumped to MLR could be very supportive for clinical decisions to safety and effectiveness of prescription of levetiracetam along the titration phase.
\end{abstract}

\section{Hosted file}

J_Macente MIPD LEV.pdf available at https://authorea.com/users/408377/articles/518418-modelinformed-precision-dosing-of-levetiracetam-in-pediatrics-population

\section{Hosted file}

J Macente Figures.pdf available at https://authorea.com/users/408377/articles/518418-modelinformed-precision-dosing-of-levetiracetam-in-pediatrics-population

\section{Hosted file}

J Macente_Tables.pdf available at https://authorea.com/users/408377/articles/518418-modelinformed-precision-dosing-of-levetiracetam-in-pediatrics-population 